\title{
«ISLAMOLATINA» . \\ LA PERCEPCIÓN DEL ISLAM EN LA EUROPA CRISTIANA. \\ TRADUCCIONES LATINAS DEL CORÁN. \\ LITERATURA LATINA DE CONTROVERSIA
}

\author{
José Martínez Gázquez \\ Universitat Autònoma de Barcelona \\ Jose.Martinez@uab.cat
}

"Islamolatina" es el nombre del equipo de investigación interuniversitaria, radicado en la UAB, que se presenta en la página web del mismo título, dirigido por el profesor José Martínez Gázquez, Catedrático de Filología Latina de la Universidad Autónoma de Barcelona sobre la percepción del Islam en la Europa latina. La denominación Islamolatina resalta el objetivo de editar y analizar los textos traducidos del árabe al latín, sean doctrinales, científicos o literarios en los que los cristianos pudieron profundizar su conocimiento de la doctrina islámica, la vida de Mahoma y el mundo musulmán, su cultura y ciencia, sus costumbres, su tradición, etc.

Cuenta con la ayuda del Proyecto de investigación financiado: "La construcción de la identidad europea occidental: Textos, Contextos y Discursos de controversia frente al Islam y el Judaismo" FFI2OII-29696-Co2-02, de la DGIGPNMIECIC, dirigido por la profa. Cándida Ferrero Hernández, coordinado con el proyecto "Desafíos de la autorrepresentación: Estrategias discursivas para la construcción de identidades en la multiconfesionalidad del SE. Europeo" FFI2OII29696-Co2-or, dirigido por el profesor Pedro Bádenas de la Peña del CSIC, "La percepció de l'Islam en la societat cristiana. Igualmente con la ayuda del SGR 200900824 de la AGAUR de la Generalitat de Catalunya, codirigido por el prof. Oscar Luís de la Curz Palma "Les traduccions llatines de l'Alcorà i la Literatura Llatina medieval de controvèrsia amb l'Islam i el Judaisme".

El grupo de investigación está formado en la actualidad por especialistas en filología latina y árabe, de la Universidad Autónoma de Barcelona, la Universidad de Barcelona y la Universidad de Alicante. Centra su trabajo en dos campos principales de trabajo:

a. El estudio y edición de los textos latinos procedentes de la traducción de los textos y fuentes directas árabes que nos permiten analizar la percepción del 
Islam y las relaciones mantenidas por la Europa cristiana medieval con los musulmanes, en especial en la Península Ibérica, en dos ámbitos

-Las traduccions latinas del Corán

-Los textos de la Vida de Mahoma.

b. El segundo campo de investigación analiza para su edición, clasificación y estudio el conjunto de los textos latinos generados por la literatura de confrontación y controversias entre cristianos, musulmanes y judíos para establecer un elenco de los autores y obras hispanas de la literatura latina de apologética y controversia de las tres religiones en conflicto.

En todos estos ámbitos de investigación la bibliografía generada sobre la imagen que la cristiandad medieval fue percibiendo sobre el Islam, ya bastante numerosa, es de difícil acceso principalmente en las fuentes, en muchas ocasiones sólo consultables en manuscrito. El grupo de investigación quiere contribuir con la publicación de estos textos y su estudio a su mejor conocimiento y empleo por parte de los investigadores de este período.

A. Corpus Islamolatinum impulsado por Pedro el Venerable (= P. V.).

Pasaron quinientos años después de la aparición del Islam hasta que Pedro el Venerable, Abad de Cluny se propuso su estudio con el propósito de proceder a su refutación. En su viaje por tierras hispanas en II42 Pedro el Venerable vio en una ciudad de la ribera del Ebro, probablemente Tarazona o Tudela la posibilidad de poner en marcha un equipo de traductores, que tradujeron un conjunto de obras directas del árabe sobre Mahoma y el Islam. Los textos traducidos forman un conjunto que llamamos Corpus Islamolatinum, al que M. Th d'Alverny erróneamente calificó como Collectio o Corpus Toletanum, ya que ninguno de estos textos fueron traducidos en Toledo. Robert de Ketton, era el responsable y traductor del Corán ayudado por Herman de Carintia y Pedro de Toledo. También participaban en este grupo, un musulmán de nombre Mohamed, y Pedro de Poitiers, secretario del Abad de Cluny, que asesoró en la redacción de los textos latinos y escribió un resumen del Liber contra sectam siue haeresim Sarracenorum escrito por el Abad, resultado del estudio de estas traducciones.

a.- Summa totius heresis ac diabolice secte sarracenorum (P. V., Petrus Pictauiensis = P. P.).

b.- Epistula domini Petri abbatis ad dominum Bernardum Clare Vallis abbatem de translatione sua qua fecit transferri ex arabico in latinum sectam siue heresim Sarracenorum (P. V.).

c.- Fabulae sarracenorum Prologus. "Cum iubendi religio..."

cI.- Chronica mendosa et ridicula sarracenorum. 
c2.- Item <Liber > de generatione Mahumet et nutritura eius, quod transtulit Hermannus sclauus, scolasticus subtilis et ingeniosus, apud legionensem Hispaniae ciuitatem (Hermannus de Karintia = H. K.). Edición: Oscar de la Cruz Palma.

d.- Doctrina: Item doctrina Mahumet, que apud sarracenos magnae auctoritatis est, ab eodem Hermanno translata, cum esset peritissimus utriusque lingue, latine scilicet atque arabice (H. K.). Edición: Cándida Ferrero Hernández.

e.- Prephacio Roberti translatoris ad dominum Petrum Cluniacensem abbatem in libro legis Saracenorum quem Alchoran uocant, id est, collectionem preceptorum (Robertus Ketennensis = R. K.).

f.- Lex ipsa: Alchoran latinus (R. K.). Edición: José Martínez Gázquez.

g.- Apologia Al-Kindi. Incipit epistula sarraceni ad suam sectam christianum inuitantis (Petrus Toletanus). Edición: Fernando González Muñoz.

h.- Epistula Petri Pictauiensis ad Petrum Abbatem (Capitula IV libri contra sectam ...) (P. P.).

i.- Liber contra sectam siue haeresim Sarracenorum (P. V.).

B. Las Traducciones Latinas del Corán.

Después de la traducción de Robert de Ketton (II43), impulsada por Pedro el Venerable como información para la refutación eclesial y teológica del Islam, aparecieron en la Europa cristiana nuevas traducciones latinas del Corán justificadas en las diversas circunstancias que fueron atravesando las relaciones entre cristianos y musulmanes en cada momento. Desde II 43 hasta I698 año en el que Ludovico Maracci publicó la última traducción latina del Corán pasaron cinco siglos, en los que las traducciones conocidas del Corán son las siguientes:

-Robert de Ketton y Pedro el Venerable (II43), Alchoranus latinus para refutación del Corán. Edición en preparación: José Martínez Gázquez.

-Marcos de Toledo (I2IO), Alchoranus Latinus para la lucha contra las Sarracenos. Edición: Nadia Petrus Pons, UAB, 2008.

-Juan de Segovia (1456), Liber Alchorani instrumento de relación pacífica con los musulmanes. Edición: José Martínez Gázquez, "El Prólogo de Juan de Segobia al Corán (Qur’an) trilingüe (I456)”, M. J., 38 (2003), pp. 389-4IO.

-Guillermo Raymundo de Moncada (c. I475), Alcoranus latinus Traducción parcial (suras 2I-22). Edición: Hartmut Bobzin, Officina di Studi Medievali, Palermo, 2008.

-Aegidius de Viterbo (Johannes Terrolensis y Leo Africanus 1518): Alcoranus latinus. Edición: Katarzyna Krystyna Starczewska, UAB, 2012.

-Guillaume Postel (I544), De orbis terrae concordia Libri quatuor. Edición en preparación: Óscar de la Cruz Palma. 
-Cirillus Lucaris (I572-I638), atribución del Alcoranus latinus fragmentario. Edición: Oscar de la Cruz Palma, Nueva Roma CSIC, Madrid, 2006.

-Dominicus Germanus de Silesia (I669), Alcorani latini Interpretatio. Edición: Antoni García Masegosa, Nueva Roma CSIC, Madrid, 2009.

C. Literatura de Controversia y confrontación cristiana, islámica y judía.

En el estudio de la literatura latina de controversia y confrontación cristiana, islámica y judía se ha iniciado un proceso gradual de estudio de las fuentes latinas directas de información de la aparición y desarrollo de estos textos, medievales y modernos en lengua latina en la sociedad cristiana hispana hasta su desenlace final con la expulsión de ambos grupos sociales, judíos y moriscos de la Península.

-Alfonsus Hispanus Bonus Homo (c. 1350). Opera Omnia Alfonsi Bonihominis Epistola Samuelis, Disputatio Abutalib, Contra Malos medicos, Historia Ioseph y Legenda Sancti Antoni. Estudio y edición en preparación: Antoni Biosca i Bas.

-Itinerarium Symonis Semeonis ab Hybernia ad Terram Sanctam (s. XIv). Candida Ferrero Hernández ha estudiado la influencia de los textos del Corpus Islamolatinum en esta obra.

- El diálogo de la fe con el sultán de los turcos. Edición: Oscar de la Cruz Palma, Nueva Roma CSIC, Madrid, 2000.

-Pedro de la Cavallería, Zelus Christi contra Iudaeos, Saracenos et Infideles (I460). Estudio y edición en preparación: Cándida Ferrero Hernández y Nuria Gómez Llauger.

-Alfonso de Espina, Fortalitium fidei contra Iudaeos, Saracenos aliosque christianae fidei inimicos (I464-I467). Estudio y edición en preparación: Raul Platas Romero.

-Pedro Guerra de Lorca, Catecheses Mystagogicae pro aduenis ex secta Mahometana (I586). Estudio, edición y traducción en preparación: Cándida Ferrero Hernández.

-Jaume Bleda Valencia, Defensio fidei in causa neophytorum siue Moriscorum Regni Valentiae (I6ro). Estudio, edición y traducción en preparación: Antoni Biosca Mas.

- La Vita Mahumet. Estudio de su transmisión y de su función en la literatura de controversia, en preparación: Oscar de la Cruz Palma.

-Marcos de Toledo, Libellum Habentometi De unione Dei translatus a Marco Toletano. Estudio y edición en preparación: José Martínez Gázquez.

\section{REFERENCIAS}

Web del proyecto con referencias a los miembros, bibliografía y actividades: $<$ http://hipatia.uab.cat/islamolatina/> 